\title{
Introducing a new method for classifying skull shape abnormalities related to craniosynostosis
}

\author{
Otto D. M. Kronig ${ }^{1}$ - Sophia A. J. Kronig ${ }^{1,2} \cdot$ Henri A. Vrooman ${ }^{3,4}$ • Jifke F. Veenland ${ }^{3,4} \cdot$ Mariëlle Jippes $^{1}$ • \\ Terence Boen ${ }^{1} \cdot$ Léon N. A. Van Adrichem ${ }^{2}$
}

Received: 6 October 2019 / Revised: 10 March 2020 / Accepted: 20 March 2020 / Published online: 17 April 2020

(C) The Author(s) 2020

\begin{abstract}
We present a novel technique for classification of skull deformities due to most common craniosynostosis. We included 5 children of every group of the common craniosynostoses (scaphocephaly, brachycephaly, trigonocephaly, and right- and leftsided anterior plagiocephaly) and additionally 5 controls. Our outline-based classification method is described, using the software programs OsiriX, MeVisLab, and Matlab. These programs were used to identify chosen landmarks (porion and exocanthion), create a base plane and a plane at $4 \mathrm{~cm}$, segment outlines, and plot resulting graphs. We measured repeatability and reproducibility, and mean curves of groups were analyzed. All raters achieved excellent intraclass correlation scores (0.994-1.000) and interclass correlation scores $(0.989-1.000)$ for identifying the external landmarks. Controls, scaphocephaly, trigonocephaly, and brachycephaly all have the peak of the forehead in the middle of the curve $\left(180^{\circ}\right)$. In contrary, in anterior plagiocephaly, the peak is shifted (to the left of graph in right-sided and vice versa). Additionally, controls, scaphocephaly, and trigonocephaly have a high peak of the forehead; scaphocephaly has the lowest troughs; in brachycephaly, the width/frontal peak ratio has the highest value with a low frontal peak.

Conclusion: We introduced a preliminary study showing an objective and reproducible methodology using CT scans for the analysis of craniosynostosis and potential application of our method to 3D photogrammetry.
\end{abstract}

What is Known:

- Diagnosis of craniosynostosis is relatively simple; however, classification of craniosynostosis is difficult and current techniques are not widely applicable.

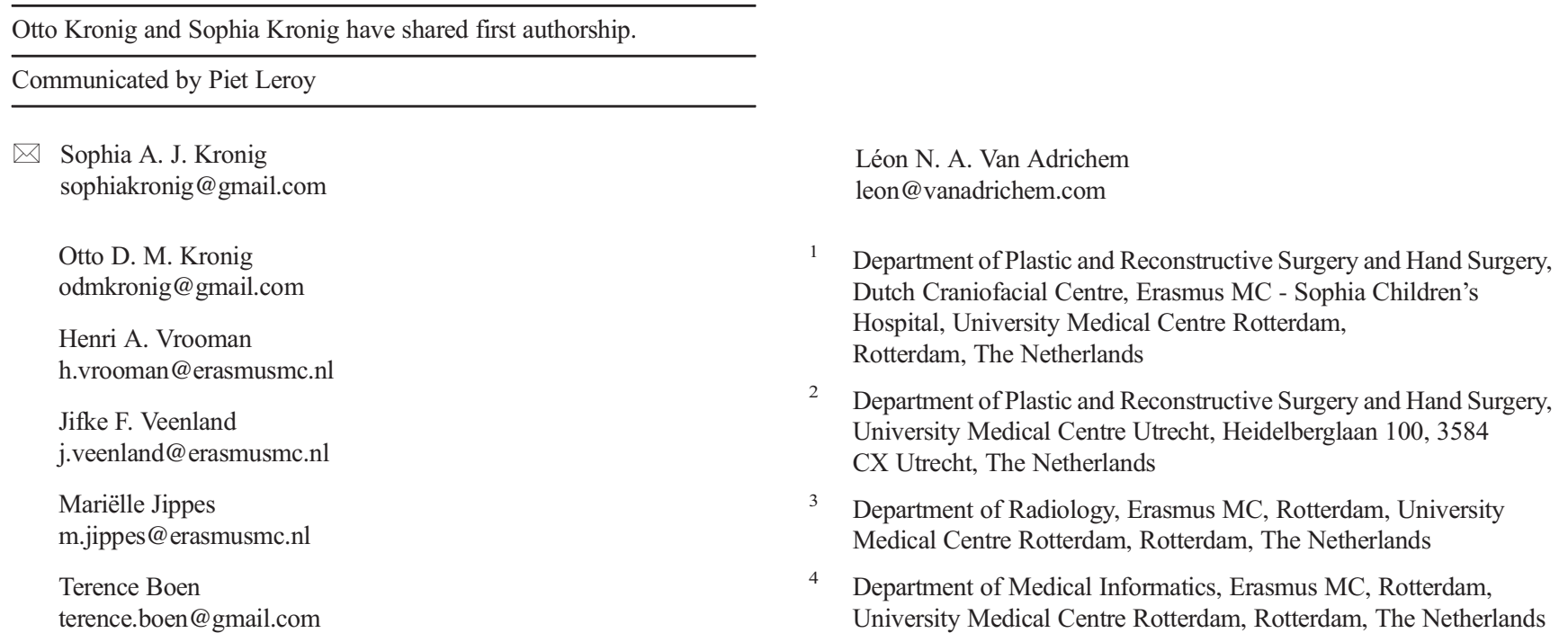


What is New:

- We introduce a novel technique for classification of skull deformities due to craniosynostosis, an objective and reproducible methodology using CT scans resulting in characteristic curves. The method is applicable to all 3D-surface rendering techniques.

- Using external landmarks and curve analysis, specific and characteristic curves for every type of craniosynostosis related to the specific skull deformities are found.

Keywords Craniosynostosis $\cdot$ Shape analysis $\cdot$ Reliability $\cdot$ Computer-assisted diagnosis $\cdot$ Computer tomography

$\begin{array}{ll}\text { Abbreviations } \\ \text { 3D } & \text { Three-dimensional } \\ \text { CI } & \text { Cranial index } \\ \text { CM } & \text { Center of mass } \\ \text { CT } & \text { Computed tomography } \\ \text { CVAI } & \text { Cranial vault asymmetry index } \\ \text { Ex } & \text { Exocanthion } \\ \text { F } & \text { Forehead peak } \\ \text { ICC } & \text { Intraclass correlation coefficients } \\ \text { ICV } & \text { Intracranial volume } \\ \text { L } & \text { Minimum value of the left side of the head } \\ \text { LS } & \text { Left-sided } \\ \text { MRI } & \text { Magnetic resonance imaging } \\ \text { O } & \text { Occiput peak } \\ \text { PCM } & \text { Plagiocephalometry } \\ \text { Po } & \text { Porion } \\ \text { R } & \text { Minimum value of the right side of the head } \\ \text { RS } & \text { Right-sided } \\ \text { SP } & \text { Starting point } \\ \text { SSI } & \text { Scaphocephaly severity index } \\ \text { XF } & X \text {-value of maximum forehead value } \\ \text { XFL } & X \text {-value for the maximum forehead minus } 0.1 \text { on the } \\ & \text { left side } \\ \text { XFR } & X \text {-value for the maximum forehead minus } 0.1 \text { on the } \\ & \text { right side } \\ \text { XL } & X \text {-value of the minimum value of the width on the left } \\ & \text { side } \\ \text { XR } & \text { X-value of the minimum value of the width on the } \\ & \text { right side } \\ & \end{array}$

\section{Abbreviations}

CI Cranial index

CT Computed tomography

try index

F $\quad$ Forehead peak

ICC Intraclass correlation coefficients

LS Left-sided

MRI Magnetic resonance imaging

Occiput peak

Po Porion

RS Right-sided

SP Starting point

XF $\quad X$-value of maximum forehead value
XFR $X$-value for the maximum forehead minus 0.1 on the right side side right side

\section{Introduction}

In normal skull development, the cranial sutures allow the brain to expand as the infant matures. In craniosynostosis patients, one or more sutures have prematurely fused to form a solid bone connection, resulting in a restriction of expansion of the cranial vault, normal growth of the brain, and deformation of the calvaria [1]. Craniosynostosis is usually diagnosed upon clinical judgment (medical history and physical examination, including anthropometry) and is confirmed by radiographic imaging.

Classification of skull shape deformities is essential and could allow for type and severity to be classified and thus may aid in clinical as well as research applicability to evaluate presentation, development, and treatment [2-7].

A variety of methods to diagnose and measure skull shape, and additionally craniosynostosis, are available; some of the currently used methods are cephalic index (CI), head circumference, intracranial volume (ICV), scaphocephaly severity index (SSI), cranial vault asymmetry index (CVAI), and the plagiocephalometry (PCM) $[3,6,8-11]$. However, these methods are not capturing the different aspects of skull shape deformity (CI, head circumference, and ICV) and are solely applicable for one specific type of craniosynostosis or positional skull deformities (SSI, CVAI, and PCM).

In this study, we will propose an outline-based method applicable for each type of craniosynostosis. A method based on the outline of the skull has the advantage of capturing the actual skull shape variation. External landmarks (soft tissue landmarks, visible with the bare eye) will be used to extract an outline of the skull shape using CT scans, resulting in sinusoid curves. These curves will be assessed for different variables specific for the most common types of craniosynostosis. Our hypothesis is that by using external landmarks in combination with the outline-based objective analysis, we are able to capture the clearly visible characteristics of craniosynostosis by all methods of 3D imaging (independent of CT imaging), enabling a repeatable and objective analysis of skull shape changes during growth and treatment.

\section{Material and methods}

\section{Patients}

For validation of external landmarks, we included 26 children (age $<1$ year). We included 24 patients with nonsyndromic craniosynostosis (11 scaphocephaly; 11 trigonocephaly; 1 brachycephaly; and 1 left-sided plagiocephaly anterior) and 2 control patients.

For analysis of the sinusoid curves, we included 25 children (age $<1$ year) with nonsyndromic craniosynostosis. Five children of every type of most common craniosynostosis (scaphocephaly, brachycephaly, trigonocephaly, and rightand left-sided (RS and LS) anterior plagiocephaly) were included. In addition, 5 control patients were included. 
For all craniosynostosis patients, a preoperative CT scan of the head needed to be available. Children with other congenital or traumatic craniofacial malformations, including multiple suture craniosynostosis, facial fractures, or soft tissue swelling, were excluded. Used CT scans were part of routine diagnostic evaluation in patients suspected for craniosynostosis.

To be eligible as control patient, the $\mathrm{CT}$ scan needed to be made at an age of 6 years or younger and needed to contain orbits and ears. These patients underwent $\mathrm{CT}$ scanning for possible neurotrauma. The scans were negative for congenital or traumatic craniofacial malformations, including craniosynostosis, facial fractures, or soft tissue swelling.

The patients were diagnosed at the Erasmus Medical Centre, Sophia Children's Hospital Rotterdam, a specialized center for treatment of a variety of skull deformities.

The study was approved by the local Medical Ethics Review Committee (MEC-2016-467). The study was deemed a retrospective clinical study and did not require formal research ethics approval under the Medical Research Involving Human Subjects Act (WMO).

\section{Repeatability and reproducibility of external landmarks}

Four external anatomic landmarks were located and marked by three different individuals, a plastic surgeon and two medical students: left and right exocanthion (ex) and left and right porion (po) (Figs. 1 and 2). This was repeated twice in different settings to get a total of three ratings per landmark, per rater, and per sample. The $x, y$, and $z$ coordinates of all ratings were recorded. To ensure repeatability and reproducibility of the external landmarks, intra- and interrater reliability were calculated.

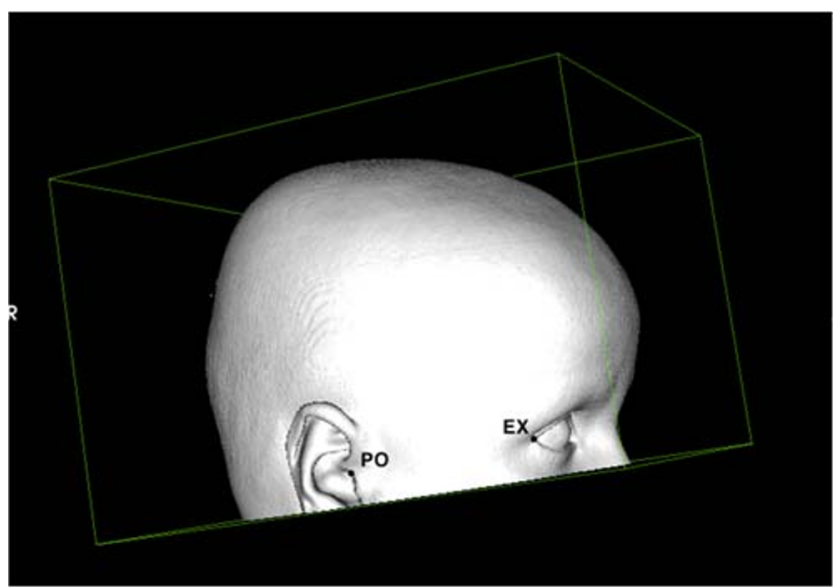

Fig. 1 The exocanthion and porion as anatomical landmarks (view from the right)

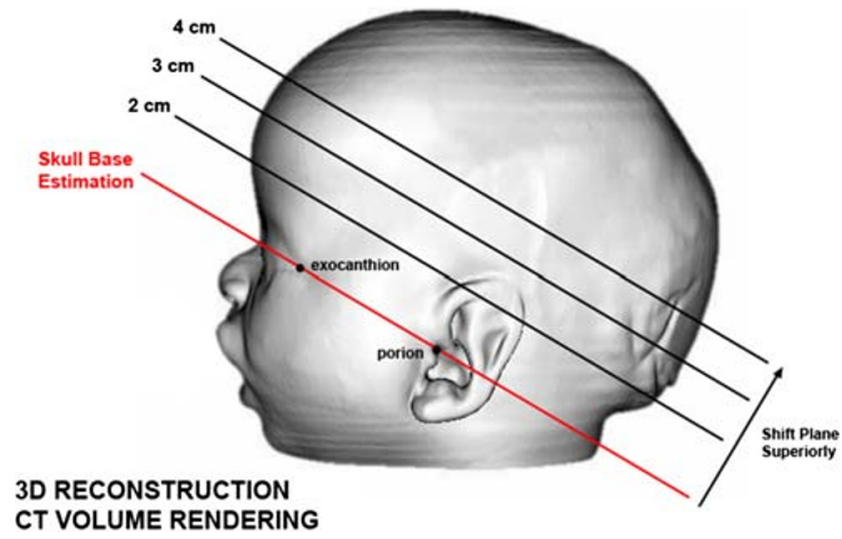

Fig. 2 Visualization of the landmarks and different heights of the planes

\section{Methodology for creating sinusoid curves}

Figure 3 shows the steps to create a sinusoid curve using external landmarks on CT scans. Figure 4 shows a visualization of the process. A requirement for defining a base plane in three dimensions is having three landmarks (with $x, y$, and $z$ coordinate). We identified four landmarks; however, for the purposes of this study, we used the following combination of landmarks: left and right exocanthion and left porion, except in left-sided plagiocephaly, the right porion was used. The plane $4 \mathrm{~cm}$ higher than the basal plane was analyzed.

The center of mass $(\mathrm{CM})$ on the $4 \mathrm{~cm}$ height planes is computed. A two-dimensional coordinate system is formed in which a distance from a reference point and an angle from a reference direction determine each point on a plane. Two (virtual) lines are drawn: one line connecting the left and right ex (Fig. 4a), and a second (virtual) line perpendicular at the middle of the first line. The point where the second line intersects the occiput determines the starting point of the curve.

Figure $4 \mathrm{c}$ shows a graphic presentation of the involved measurements and resulting plot. The sinusoid corresponds to the shape of the skull outline and is the foundation for craniosynostosis analysis.

Absolute curves of the skull outlines were transformed to relative curves in order to achieve results independent of skull size and therefore age. A value of 1.0 represents the mean value, and values lower or higher than 1.0 represent a value lower respectively higher than the mean value. The $x$-axis of the plot shows the angle from a reference direction; the $y$-axis shows relative values of the distance from the $\mathrm{CM}$. This information will result in a sinusoid curve (Fig. 4c).

\section{Analysis}

Table 1 shows the obtained and specific values extracted from the curves; these values are used for analysis of the curves specific for each type of craniosynostosis. 


\section{Pre-operative CT-scan}

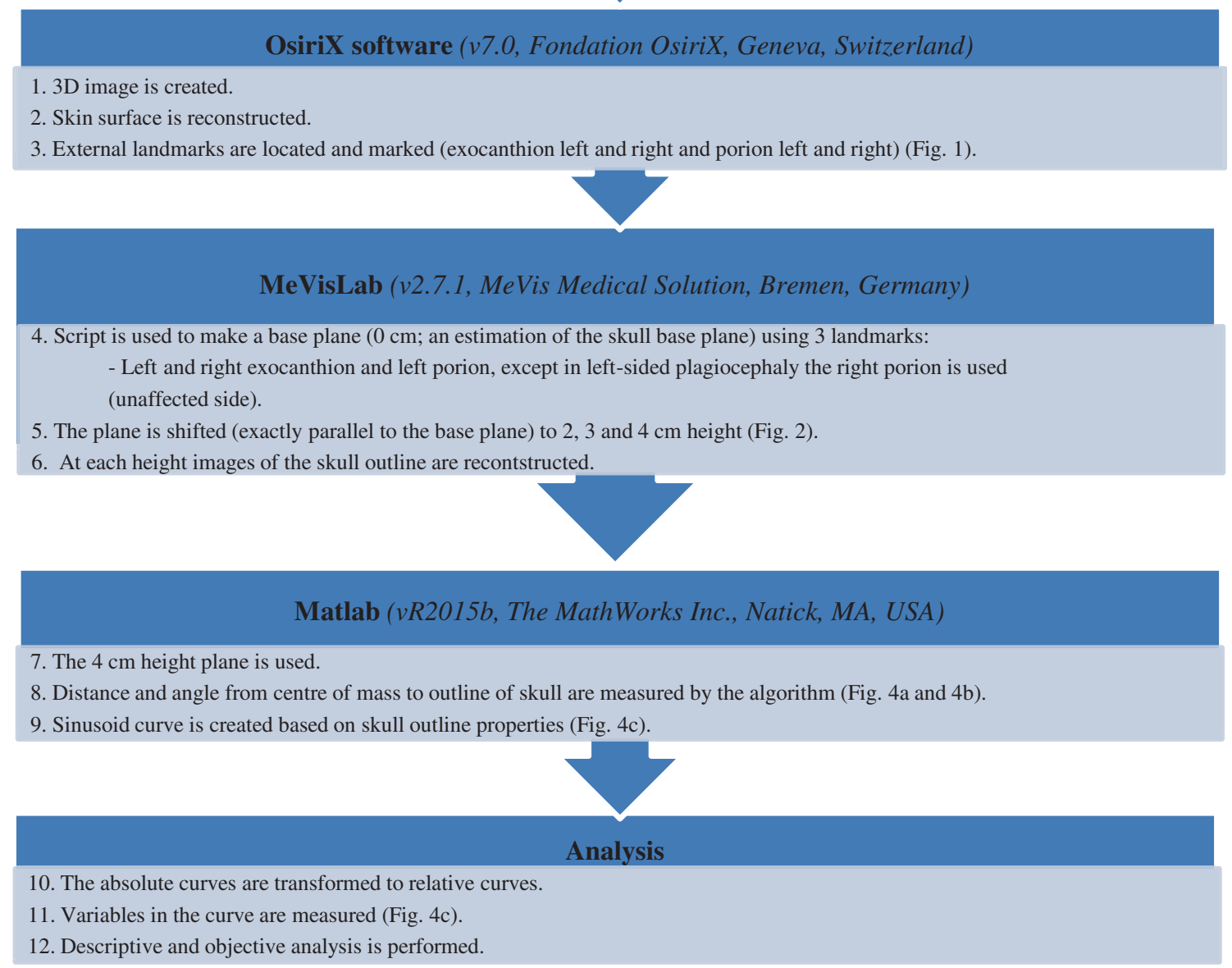

Fig. 3 Summary of methods

For each type of skull shape, the mean, minimum, and maximum values were established for all curves and for extracted and calculated values. Mean difference of the $y$-value for each patient group for every degree ( $x$-axis) is calculated. We determine if the peak of the forehead is at $180^{\circ} \pm 12$.

\section{Statistical analysis}

Statistical analyses were performed using the SPSS for Windows (Version 21, SPSS Inc., Chicago, IL, USA). We calculated intrarater reliability for the placed landmarks and interrater reliability to compare reliability between the three sessions of placing landmarks. Data regarding intra- and interrater reliability were analyzed with intraclass correlation coefficients (ICC) with acceptable reliability criteria $>0.75$ [12]. Using SPSS, the two-way random effects model was used; absolute agreement and single measures were used. The results of all the extractions and calculations of the groups were compared, and the mean values (of range) of each patient group are compared using one-way ANOVA and appropriate post hoc tests; Bonferroni correction was used with alpha $=$
0.05 (SPSS for Windows (Version 21, SPSS Inc., Chicago, IL, USA)).

\section{Results}

\section{Repeatability and reproducibility}

Locating of landmarks was done in triplicate by three raters. All raters achieved excellent intraclass correlation scores (0.994-1.000) and excellent interclass correlation scores (0.989-1.000).

\section{Overview curves}

Figure $4 \mathrm{c}$ shows an example of an obtained curve. The curve starts at the occiput and skull outline is followed clockwise. After the first peak, resembling the occiput, the curve decreases, because the distance from the $\mathrm{CM}$ to the right side of the head is shorter than the distance from CM to the forehead or occiput. The second peak resembles the forehead; 
Fig. 4 Visualization of the starting point of the curve and the resulting sinusoid curve; the outline was made with the slices shown in Fig. 4b. a Plane on $0 \mathrm{~cm}$ height; this figure shows how the starting point of the curve is determined. Also, the degrees of the circle/outline are added, which are represented in the curve. b Plane on $4 \mathrm{~cm}$ height; this figure shows the starting point and the direction of the curve. c The resulting curve. The different variables are marked. Curve starts at the occiput (SP; Fig. 4b) and follows the skull outline (on CT scan) clockwise; therefore, the first trough represents the right side of the head. The second peak is the forehead; the second trough is the left side of the head. Curve stops where it started (at the occiput).
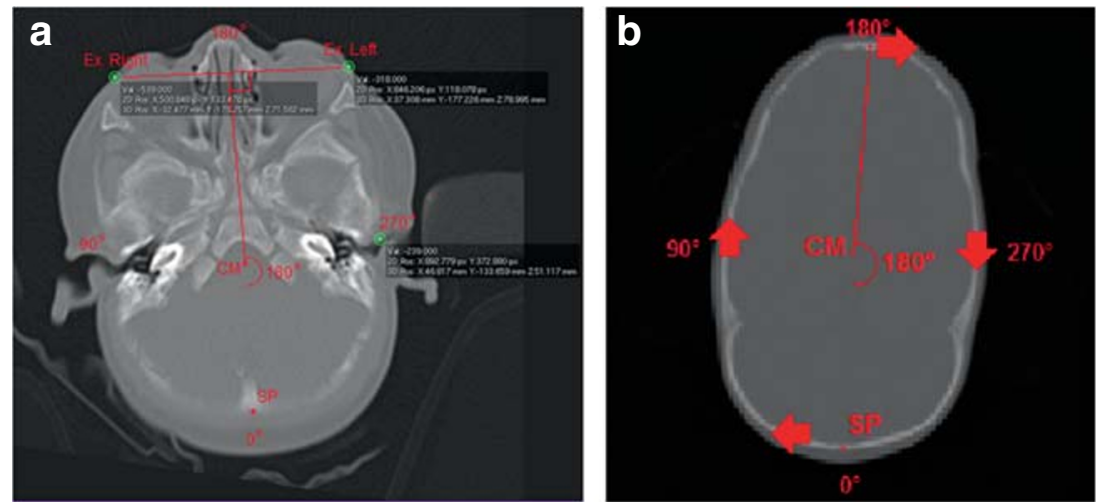

$\mathrm{CM}=$ Centre of Mass; $\mathrm{SP}=$ Starting Point

C

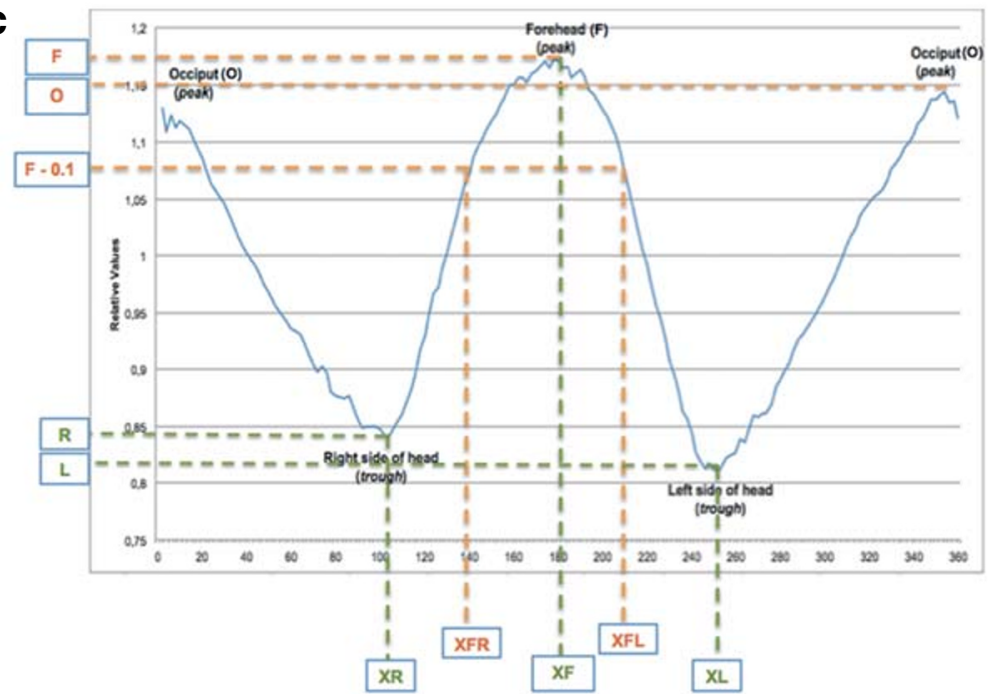

again the curve decreases to the left side of the head and increases to the occiput (Fig. 4c).

Figure 5 shows an overview of curves of the mean values of each subgroup. Each subgroup includes 5 patients; patient characteristics can be found in Table 2. For all patients, variables are extracted and calculated using the resulting curves. Only notable characteristics of the curves of each subgroup will be discussed.

\section{Control patients}

The length of the skull is $30.5 \%$ longer than the width of the skull. Peaks of the forehead and occiput are of equal height. Mean width of forehead ratio is 78.61 (64.99-92.91). Mean asymmetry ratio is $1.05(0.93-1.26)$, with the peak of the forehead in the middle of the curve $\left(180^{\circ} \pm 12\right)$.

\section{Scaphocephaly}

Both the forehead (1.16) and occiput are relatively long (1.24: the longest of all groups); the difference is -0.08 . The width is relatively small (mean $=0.81$, the lowest of groups). The length of the skull is $48.5 \%$ longer than the width of the skull.
The difference between the occiput and sides of the head is the highest (0.43). Mean width of forehead ratio is 84.59 (73.6098.04). Mean asymmetry ratio is $1.02(0.96-1.09)$, with the peak of the forehead in the middle of the curve $\left(180^{\circ} \pm 12\right)$.

\section{Trigonocephaly}

The forehead is relatively long $(1.18=$ highest mean $)$, the occiput is slightly shorter (1.09), and the difference is 0.09 . Width is normal (mean $=0.89$ ), and the length of the skull is $27.2 \%$ longer than the width. Difference between the occiput and sides of the head is slightly less than normal (0.20). Mean width of forehead ratio is 47.95 (34.33-65.95), and mean asymmetry ratio is $1.39(1.31-1.52)$, with the peak of the forehead in the middle of the curve $\left(180^{\circ} \pm 12\right)$.

\section{Anterior plagiocephaly}

Both the forehead (1.11 RS and 1.11 LS) and occiput (1.11 RS and $1.09 \mathrm{LS}$ ) are slightly short. Difference is $0.01 \mathrm{RS}$ and $0.02 \mathrm{LS}$. Width is broader (mean 0.90 RS and 0.91 LS). The length of the skull is $23.0 \%$ RS and $20.6 \%$ LS longer than width in RS and LS. Difference between the occiput and sides of the head is slightly 
Table 1 Extracted and calculated variables from curve

\begin{tabular}{|c|c|c|c|}
\hline \multicolumn{4}{|l|}{ Length and width } \\
\hline Variable & Abbreviation & Variable & Abbreviation \\
\hline Maximum value of forehead peak & $\mathrm{F}$ & Minimum value of the right side of the head (trough) & $\mathrm{R}$ \\
\hline Maximum value of occiput peak & $\mathrm{O}$ & Minimum value of the left side of the head (trough) & $\mathrm{L}$ \\
\hline \multicolumn{4}{|l|}{ Calculations } \\
\hline Calculated variable & Formula & Calculated variable & Formula \\
\hline Mean of both sides & $\mathrm{R} / 2+\mathrm{L} / 2$ & Total maximum length & $\mathrm{F}+\mathrm{O}$ \\
\hline Difference of the occiput and sides & $\mathrm{O}-(\mathrm{R} / 2-\mathrm{L} / 2)$ & Difference of the forehead and sides & $\mathrm{F}-(\mathrm{R} / 2-\mathrm{L} / 2)$ \\
\hline $\begin{array}{l}\text { Total minimum value in curve of width (max. } \\
\text { clinical width) }\end{array}$ & $\mathrm{R}+\mathrm{L}$ & $\begin{array}{l}\text { Minimum value (in curve of) width/maximum length ratio } \\
\text { (comparable with cranial index) }\end{array}$ & $(\mathrm{R}+\mathrm{L}) /(\mathrm{F}+\mathrm{O})$ \\
\hline Difference of the forehead and occiput & $\mathrm{F}-\mathrm{O}$ & Ratio length to width of the skull & $(\mathrm{F}+\mathrm{O}) /(\mathrm{R}+\mathrm{L})$ \\
\hline \multicolumn{4}{|l|}{ Forehead shape analysis } \\
\hline Variable & Abbreviation & Variable & Abbreviation \\
\hline $\begin{array}{l}X \text {-value (in degrees) of the maximum forehead } \\
\text { value }\end{array}$ & $\mathrm{XF}$ & $\begin{array}{l}X \text {-value (in degrees) for maximum forehead minus } 0.1 \\
\text { (F-0.1) on the left side }\end{array}$ & XFL \\
\hline $\begin{array}{l}X \text {-value (in degrees) for maximum forehead minus } \\
0.1(\mathrm{~F}-0.1) \text { on the right side } \\
\text { Calculations }\end{array}$ & XFR & & \\
\hline Calculated variable & Formula & & \\
\hline Width of the forehead & $(\mathrm{XFL}-\mathrm{XFR}) /(\mathrm{F}-0.1)$ & & \\
\hline \multicolumn{4}{|l|}{ (A)symmetry analysis } \\
\hline Variable & Abbreviation & Variable & Abbreviation \\
\hline $\begin{array}{l}X \text {-value (in degrees) of minimum value of width on } \\
\text { right side } \\
\text { Calculations }\end{array}$ & $\mathrm{XR}$ & $\begin{array}{l}X \text {-value (in degrees) of minimum value of width on the left } \\
\text { side }\end{array}$ & $\mathrm{XL}$ \\
\hline Calculated variable & Formula & & \\
\hline Asymmetry ratio & $(\mathrm{XF}-\mathrm{XR}) /(\mathrm{XL}-\mathrm{XF})$ & & \\
\hline
\end{tabular}

less than normal ( $0.20 \mathrm{RS}$ and $0.18 \mathrm{LS})$. Mean width of forehead ratio is 83.44 (49.99-131.75) in $\mathrm{RS}$ and 96.42 (59.77-172.94) in LS. Mean asymmetry ratio is $1.82(1.32-2.43)$ in RS and 0.55 $(0.41-0.70)$ in LS, with the peak of the forehead deviated $>12^{\circ}$ less than $180^{\circ}\left(<168^{\circ}\right)$ RS and $>12^{\circ}$ more than $180^{\circ}\left(>192^{\circ}\right)$ LS.

\section{Brachycephaly}

Both the forehead $(1.08=$ lowest mean $)$ and occiput are short $(1.09=$ lowest mean); the difference is 0.00 , meaning the peaks of the forehead and occiput are of equal height. The width is high (mean $=0.91$ ). The length of the skull is $19.5 \%$ longer than width. Difference between the occiput and sides of the head is less than normal $(0.18=$ lowest mean $)$. Mean width of forehead ratio is 123.02 (68.72-169.14). The asymmetry ratio is $1.11(0.93-1.21)$, with the peak of the forehead in the middle of the curve $\left(180^{\circ} \pm 12\right)$.

\section{Comparison of means}

Mean difference between maximum and minimum values (i.e., range) in the curve for each degree in control patients was 0.12 (SD 0.04), in scaphocephaly 0.08 (SD 0.02), in trigonocephaly 0.08 (SD 0.03), in LS 0.07 (SD 0.02) and in RS 0.08 (SD 0.02) anterior plagiocephaly and in brachycephaly 0.07 (SD 0.03).

When comparing mean differences, one-way ANOVA showed significant difference between subgroups $(p<0.001)$. Following, Levene's test showed assumption of homogeneity of variances between the groups was violated $(p<0.001)$. Therefore, Games-Howell test was performed as post hoc test and additionally Bonferroni correction. This showed the mean of control group was significantly higher than in all other patient groups $(p<0.001)$. Also, significant differences in means between the left-sided anterior plagiocephaly and right-sided anterior plagiocephaly, trigonocephaly, and scaphocephaly (all $p<0.001$ ) were found.

\section{Discussion}

In the present study, we introduced a new methodology for analyzing and diagnosing skull deformities using external 
Fig. 5 Overview mean graphs of all patient groups and controls

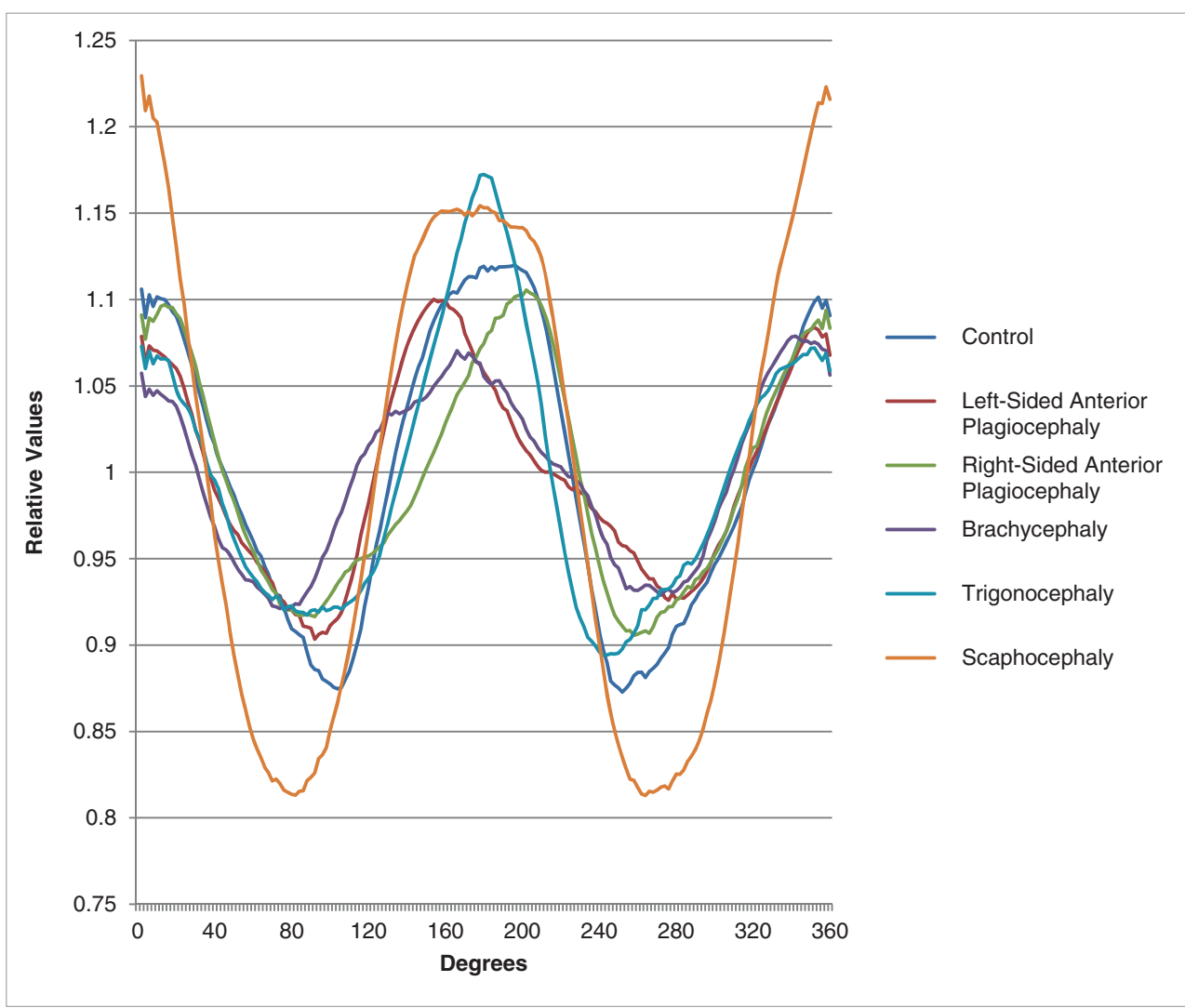

landmarks and a two-dimensional skull shape outline. Until now, no accurate method of measurement for skull shape was available applicable to all types of craniosynostosis. Additionally, there was no valid comparative method for skull shape. Therefore, the purpose of this study was to develop a new method of measurement that makes comparative analysis possible in both craniosynostosis and control patients.

As stated before, currently widely used methods of measurement are CI and head circumference [3, 8, 9]. Other proposed methods are SSI, CVAI, and PCM $[6,10,11]$. However, these latter methods are only applicable for scaphocephaly, anterior plagiocephaly, or positional skull deformations and therefore not generalizable to most common craniosynostosis diagnoses.

When assessing the potential for proper classification of different types of craniosynostosis, a key issue arises. Both CI and CVAI are widely used in clinical settings, since they are fast, cheap, and easily applicable [13, 14]. However, measurements and calculations only using greatest width and greatest length (CI) or cranial diagonal diameters (CVAI) do not capture the actual shape of deformity, and additional quantification is necessary $[6,10,15]$.

Another well-established morphometric parameter for skull growth is head circumference. The measurement is taken around the largest part of the head, above the eyebrows, above the ears, and the most posterior part of the head. It is another fast, easy, and cheap method but also discarding other features of dysmorphology [9].

ICV is another used method; however, volume gives no additional information about the skull shape and in craniosynostosis, compensatory growth will occur in a direction parallel to a fused suture and this explains why ICV is often within normal range in children with craniosynostosis [8, 16].

Table 2 Patient Characteristics

\begin{tabular}{lll}
\hline Patient Group & Age (months) (mean (min. - max. $))$ & Sex (male vs. female) \\
\hline Control patients & $49(37-66)$ & 5 vs. 0 \\
Scaphocephaly & $5.2(2-9)$ & 5 vs. 0 \\
Trigonocephaly & $4.6(1-8)$ & 3 vs. 2 \\
Anterior plagiocephaly & $7.9(2-18)$ & 1 vs. 9 \\
Brachycephaly & $3.8(2-5)$ & 1 vs. 4 \\
\hline
\end{tabular}


An outline-based approach, such as our proposed method, has the advantage that it can account for complex geometric variations in shape. External landmarks were chosen, in order to evolve our method to using $3 \mathrm{D}$ photogrammetry in the future. Using $3 \mathrm{D}$ photogrammetry, there is no need to expose the young patient to irradiation (CT scans) or general anesthesia (MRI) and its consequences [7, 17-20]. Accuracy of anthropometry is depending on the accurate identification and reliability of anatomical landmarks. The used exocanthion and porion are external landmarks, clearly identifiable without palpation, and are widely accepted [9]. Based on our consensus, we used LS and RS exocanthion and LS porion. However, in left-sided plagiocephaly, we used RS porion, because this side was unaffected by the skull deformity. Slices at $4 \mathrm{~cm}$ height gave the most proper outline of the skull without orbital disturbance and were used.

We calculated repeatability and reproducibility of our proposed methodology. This is a first step in validation, and further validation is essential in implementing a new approach for classification of congenital skull malformations. Based on the selected external landmarks, we found both excellent repeatability and reproducibility (intra- and interrater reliability) and this method can therefore be used to create valid twodimensional slice images for skull shape outline.

We determined if the peak of the forehead is around $180^{\circ} \pm$ $12^{\circ}$. This value of $12^{\circ}$ is supported by our results and corresponds to the used value of asymmetry of $>3.5 \%$ in the CVAI (3.5\% of $360^{\circ}$ corresponds to a value of 12.6 ), which shows significantly asymmetrical values of the head in plagiocephaly patients [10]. A notable finding in this study is the asymmetry ratio of trigonocephaly patients (Fig. 5). In these patients, the peak of the forehead is located at $180^{\circ} \pm 12^{\circ}$; however, the relatively high asymmetry ratio shows values comparable with right-sided anterior plagiocephaly. In future research, we will focus on the cause of this finding, e.g. coexisting positional plagiocephaly or incidental finding.

Range between maximum and minimum values of curves is (statistically significant) larger in the control group than in other patient groups. This can be explained by a (wide) normal variation in skull shapes in normal children, whereas craniosynostosis patients have growth restriction in one direction and accelerated compensatory growth in the perpendicular direction.

We have presented a new approach for diagnosing different types of craniosynostosis. We can conclude that every type of craniosynostosis has a specific and recognizable skull deformity, and therefore we can identify a trend towards a specific and characteristic pattern of the curve for the different types. Based on the curve and values contributing to the curve, our novel method is a promising tool in diagnosing craniosynostosis. This method could be a useful tool in the field of research of craniosynostosis and in the clinical setting. By using external landmarks, future research using $3 \mathrm{D}$ photogrammetry to create a $2 \mathrm{D}$ skull outline is a promising non-invasive alternative, which can be used for monitoring growth and surgical results and potentially quantifying severity of craniosynostosis. However, further research is necessary with a larger group of patients in order to further analyze and validate our method and to be generalizable for a larger group of patients.

Authors' contributions L.N.A. Van Adrichem conceived the study. L.N.A. Van Adrichem, O.D.M. Kronig, and S.A.J. Kronig designed the study. L.N.A. Van Adrichem, O.D.M. Kronig, S.A.J. Kronig, M. Jippes, and T. Boen collected the data. H.A. Vrooman and J.F. Veenland programmed the computer methods. L.N.A. Van Adrichem, O.D.M. Kronig, and S.A.J. Kronig performed data interpretation. O.D.M. Kronig and S.A.J. Kronig wrote the first manuscript draft. All authors provided intellectual input, contributed to manuscript revisions, and approved the final manuscript.

\section{Compliance with ethical standards}

Conflict of interest The authors declare that they have no conflict of interest.

Ethical approval This study was deemed a retrospective clinical study by the local Medical Ethics Review Committee and did not require ethics approval according to the Medical Research Involving Human Subjects Act (WMO) (MEC-2016-467).

Informed consent Not required.

Open Access This article is licensed under a Creative Commons Attribution 4.0 International License, which permits use, sharing, adaptation, distribution and reproduction in any medium or format, as long as you give appropriate credit to the original author(s) and the source, provide a link to the Creative Commons licence, and indicate if changes were made. The images or other third party material in this article are included in the article's Creative Commons licence, unless indicated otherwise in a credit line to the material. If material is not included in the article's Creative Commons licence and your intended use is not permitted by statutory regulation or exceeds the permitted use, you will need to obtain permission directly from the copyright holder. To view a copy of this licence, visit http://creativecommons.org/licenses/by/4.0/.

\section{References}

1. Slater BJ, Lenton KA, Kwan MD, Gupta DM, Wan DC, Longaker MT (2008) Cranial sutures: a brief review. Plast Reconstr Surg 121(4):170e-178e

2. Bottero L, Lajeunie E, Arnaud E, Marchac D, Renier D (1998) Functional outcome after surgery for trigonocephaly. Plast Reconstr Surg 102(4):952-958 discussion 9-60

3. Kolar JC, Salter EM (1997) Preoperative anthropometric dysmorphology in metopic synostosis. Am J Phys Anthropol 103(3):341-351

4. Posnick JC, Lin KY, Chen P, Armstrong D (1994) Metopic synostosis: quantitative assessment of presenting deformity and surgical results based on CT scans. Plast Reconstr Surg 93(1):16-24

5. Ruiz-Correa S, Starr JR, Lin HJ, Kapp-Simon KA, Cunningham ML, Speltz ML (2007) Severity of skull malformation is unrelated to presurgery neurobehavioral status of infants with sagittal synostosis. Cleft Palate Craniofac J. 44(5):548-554 
6. Ruiz-Correa S, Sze RW, Starr JR, Lin HT, Speltz ML, Cunningham ML, Hing AV (2006) New scaphocephaly severity indices of sagittal craniosynostosis: a comparative study with cranial index quantifications. Cleft Palate Craniofac J 43(2):211-221

7. Weinzweig J, Kirschner RE, Farley A, Reiss P, Hunter J, Whitaker LA, Bartlett SP (2003) Metopic synostosis: defining the temporal sequence of normal suture fusion and differentiating it from synostosis on the basis of computed tomography images. Plast Reconstr Surg 112(5):1211-1218

8. Gault DT, Renier D, Marchac D, Ackland FM, Jones BM (1990) Intracranial volume in children with craniosynostosis. J Craniofac Surg 1(1):1-3

9. Kolar JCSE (1997) Craniofacial anthropometry: practical measurement of the head and face for clinical, surgical, and research use. CC Thomas, Springfield

10. Loveday BP, de Chalain TB (2001) Active counterpositioning or orthotic device to treat positional plagiocephaly? J Craniofac Surg 12(4):308-313

11. van Adrichem LN, van Vlimmeren LA, Cadanova D, Helders PJ, Engelbert RH, van Neck HJ et al (2008) Validation of a simple method for measuring cranial deformities (plagiocephalometry). J Craniofac Surg 19(1):15-21

12. Portney LGWM (2000) Foundations of clinical research: applications to practice, 2nd edn, Upper Saddle River

13. McGarry A, Dixon MT, Greig RJ, Hamilton DR, Sexton S, Smart H (2008) Head shape measurement standards and cranial orthoses in the treatment of infants with deformational plagiocephaly. Dev Med Child Neurol 50(8):568-576

14. van Lindert EJ, Siepel FJ, Delye H, Ettema AM, Berge SJ, Maal TJ et al (2013) Validation of cephalic index measurements in scaphocephaly. Childs Nerv Syst 29(6):1007-1014

15. Maugans TA, McComb JG, Levy ML (1997) Surgical management of sagittal synostosis: a comparative analysis of strip craniectomy and calvarial vault remodeling. Pediatr Neurosurg 27(3):137-148

16. Sgouros S, Hockley AD, Goldin JH, Wake MJ, Natarajan K (1999) Intracranial volume change in craniosynostosis. J Neurosurg 91(4): 617-625

17. Baldwin RT, Preston-Martin S (2004) Epidemiology of brain tumors in childhood-a review. Toxicol Appl Pharmacol 199(2):118 131

18. Riphagen JM, van Neck JW, van Adrichem LN (2008) 3D surface imaging in medicine: a review of working principles and implications for imaging the unsedated child. J Craniofac Surg 19(2):517524

19. Schull WJ, Otake M (1999) Cognitive function and prenatal exposure to ionizing radiation. Teratology. 59(4):222-226

20. Seibert JA (2004) Tradeoffs between image quality and dose. Pediatr Radiol 34(Suppl 3):S183-S195 discussion S234-41

Publisher's note Springer Nature remains neutral with regard to jurisdictional claims in published maps and institutional affiliations. 